\title{
The Study on Recessive Financial Capital: "The Capital Structure Puzzle” Based Perspective
}

\author{
Deng Jie \\ College of Economics \& Management \\ Beijing University of Chemical Technology \\ Beijing 100029
}

\author{
Deng Xiaojun \\ College of Economics \& Management \\ Xi'an Shiyou University \\ Xi'an Shaanxi 710065
}

\begin{abstract}
This paper manages to research the value and feasibility of the study on recessive financial capital through the perspective of "the capital structure puzzle" based on the gaps of research status on recessive financial capital. For this purpose, based on the combing and analyzing the reference system of the current recessive financial capital research and the field research on capital structure value decision of relationship capital, customer capital, reputational capital of Petrochina Shaanxi Marketing Company and China Mobile Shaanxi Ltd, this paper has observed that the era of knowledge economy have some uncertainties on the estimation of financial value of recessive financial capital, such as relationship capital, customer capital, reputational capital which have made great contribution to the financial value of a venture. In other words, the value decision practice of enterprise capital structure is difficult to gage the financial value contributing degree towards relationship capital, customer capital and reputational capital. However, its result is directly related to the "noise" and "capital structure puzzle" of the financial value contributing degree of recessive financial capital, such as the relationship capital, customer capital and reputational capital. Therefore, the objective existence of "capital structure puzzle" is not only the direct theoretical ground for driving the research of recessive financial capital, but also provides a new analysis perspective for solving the "capital structure puzzle”.
\end{abstract}

Keywords-the capital structure puzzle; recessive financial capital; financial value "noise"

\section{INTRODUCTION}

The essence of finance is a process of creating value for enterprises through integration, optimization and decision of all kinds of capital elements in enterprises to adjust to the dynamic external and internal finance environment in financial decision activities. In the year of 1958, the publishing of the classic masterpiece The Cost Of Capital, Corporation Finance And The Theory Of Investment by Modigliani \& Miller1 and the capital structure theory system which is constantly amended and improved by the following researchers first systematically revealed the logical proposition between different financing capital structure of enterprises and enterprise value and lied a solid theoretical foundation for the creation and capital rationing decision of the financial value of enterprises, which has marked the milestone of the modern financial value decision science transferring from qualitative description to quantitative measure. However, the beginning of the capital structure theoretical system of modern finance theoretical benchmarking research has limited guidance value for financial value decision practice. The research results indicate that there is a weak relationship between capital structure theoretical system and financial value decision practice of enterprises. So that the logical proposition research of capital structure-value creation and the research of IPO and dividend distribution have become the unsolved puzzles in modern finance. Based on the perspective of the creation of enterprise endogenous worth, ignoring the research of relationship between recessive off balance sheet financial capital and enterprise value undoubtedly is undoubtedly the fundamental reason for causing the "capital structure puzzle". Therefore, the research and analysis of logic relationship between financial capital and the creation of enterprise endogenous worth based on the perspective of the recessive financial capital may be the feasible thought and method to solve "the capital structure puzzle”.

\section{The Origin OF "The Capital StRucture PuZzle”}

Stewart C. Myers puts forward an idea of "the capital structure puzzle" in his masterpiece The Capital Structure Puzzle: 1. "The capital structure puzzle is tougher than the dividend one...By contrast we know very little about capital structure. we do not know how firms chose the debt, equity or hybrid securities they issue." 2. "we have only recently discovered that capital structure changes convey information to investors. There has been little if any research testing whether the relationship between financial leverage and investors, returns is as pure MM theory predicts. 3. In general, we have inadequate understanding of corporate financing behavior, and of how that behavior affects security returns.” Myers holds that "the capital structure puzzle" which caused the three puzzles in western modern finance lies in MM theory is impossible to expect the relationship between financial leverage and the expected return of financial capital investor and the lacking of the empirical test of this uncertain interactive relationship. In fact, because the amount of finance resource elements owned or controlled by companies in reality cannot be completely same and so as the financial tactics in different companies, such as financing channels, the tactic selection of financing method. The totally different financial leverages of different companies are unique. Considering the financial distress cost and the uncertain agency cost as Myers casting aside the "managers assumption" in his masterpiece and Miler put forward "neutral catastrophe theory assumption" in the year of 1977 shows that the feasible approach to solve "the capital 
structure puzzle" lies in the uncertain financial capital in the capital structure, and that is the research of the relationship between recessive financial capital and the creation of enterprise value.

\section{The CAPITAl Structure PuZzLE AND THE Research OF RECESSIVE FINANCIAL CAPITAL}

In fact, the ice-breaking move of solving " the capital structure puzzle" is Capital Structure Irrelevance Theory put forward by Modigliani \& Miller in 1958. Therefore, with the classification identifier of the forming of "the capital structure puzzle" , the development and evolvement of western capital structure theory can be divided into two stages based on the proposal of MM theory: The theory before MM theory and the theory system after MM theory.

\section{A. Capital Structure Theory before the MM Theory}

The theory before the MM theory begins at the classic paper Enterprise Debt and Shareholders' Equity Cost: Tendency and the Metering Problem by David Durand. In this paper, David Durand put forward three different theories, NIT theory, NOIT theory and TCT theory after summarizing the existing research literature of financial capital theory. The financial capital theory of this period is the scattered thoughts and viewpoints towards some aspects of capital structure problems concluded by scholars in an intuitionistic perspective. And the content lacks of completeness and systematicness. Therefore, it did not form a complete theory system. In the meanwhile, the theory before MM theory which lacks theoretical logic model and the support of empirical statistical analysis determines that it has minimal guiding significance on the decision practice of enterprise financial value. This has formed the theoretical premise of "the capital structure puzzle".

\section{B. Capital Structure Theory after the MM Theory}

The theory system after the MM theory begins at the capital structure irrelevance theory put forward by Modigliani \& Miller in 1958. The multi-angle modification and improvement of capital structure irrelevance theory has formed three capital structure theoretical paradigms while three important developing phases of capital structure irrelevance theory are happening. These three capital structure theoretical paradigms are: extrinsic research paradigm of capital structure theory; intrinsic research paradigm of capital structure theory; extrinsic and intrinsic research paradigm of capital structure theory.

1) Extrinsic research paradigm of capital structure theory. This theory system includes relevant capital structure, regression theory of Miller and static trade off theory. This mode begins at gradually loosing the serial assumed conditions of MM capital structure irrelevance theory which are hyper-abstract and highly deviated from the real economic life. Based on the marginal analysis paradigm of neoclassical economics, importing two new varieties of taxation earning and bankruptcy cost into the capital structure irrelevance theory forms the capital structure tax shield paradigm of researching the correlation among taxation earning, capital structure and financial value and the capital structure financial distress paradigm of researching the correlation among financial distress cost, capital structure and financial value. At last these two research paradigms are reaching to the same static trade off theory. Extrinsic research paradigm discusses the balance proposition of the prospective earnings of debt capital and debt capital cost based on the elements of tax law and bankruptcy law in the external financial environment of enterprises. When the earnings of debt capital equals to the debt capital cost, the adding of enterprise value and the financial distress cost caused by exogenous debt financing will be the same. At this time, the balance point is correspond to enterprises' best capital structure. Certainly, because of the different capital structure of different enterprises, extrinsic research paradigm holds that the target debt ratio of different enterprises and different target capital structure may be totally different, by which it causes the difference of the exogenous combination of financing forms of different enterprises. Therefore, the enterprises with the physical capital taking a large proportion in the whole financial capital or with more taxation earning cash flow will have a higher target leverage and are more prone to debt financing. In contrast, the enterprises with the intangible capital taking a large proportion in the whole financial capital or with less taxation earning cash flow will have a lower target leverage and are more prone to equity financing. The sight of research is just limited to the external financial environment of enterprises, such as taxation earning and bankruptcy cost. Besides, the empirical evidence and financial value decision practice all indicate that the target leverage ratio of profit-making enterprises is lower than that of the loss-generating enterprises in the same line of business. This is contradicting to the results gained from the extrinsic research paradigm of capital structure theory. Because these two irreparable and unsolved defects, the extrinsic research paradigm of capital structure theory has been gradually replaced by the intrinsic research paradigm of capital structure theory.

2) Intrinsic research paradigm of capital structure theory. The theoretical system is mainly composed of agency cost theory, signal transmission theory and pecking order theory. Intrinsic research paradigm starts from the internal financial factors of enterprises, such as financial signaling stimulus, the motivation of signing financial contract. It manages to analyze the financial interest game behavior of different stakeholders of enterprises in the capital structure trade-off theory based on the partial equilibrium method of new-classic economics. To regularize the uncertainties of game behavior caused by information asymmetry of each interest game players in financial interest game based on the design of financial contract system. Extrinsic research paradigm of the capital structure theory has realized the static tradeoff structural transformation and system design, which has opened up a new direction for capital structure theory research. Therefore, it is the negation of negation of the extrinsic research paradigm. 
3) Extrinsic and intrinsic research paradigm of capital structure theory. The theoretical system is mainly composed of financial control power theory, industrial organizational theory and market timing theory. In essence, the extrinsic and intrinsic research paradigm of capital structure theory is the eclectic and compromised product of extrinsic research paradigm and intrinsic research paradigm: on one hand, extrinsic and intrinsic research paradigm manages to challenge and amend the limitations of extrinsic research paradigm and intrinsic research paradigm and form a new framework of capital structure theory research under the background of that intellectual capital plays a more salient role in creating the value in the era of knowledge economy. But it cannot get rid of or break through the constraints of the information asymmetry in intrinsic research paradigm, which is a core point of support; on the other hand, denying and sublating the established research results of all kinds of research paradigms of capital structure theory and incorporating all the existing research thoughts and ideas of each schools which are in direct line of capital structure theory to restraint the deviation trend is the core topics of this research paradigm.

Based on the combing of the evolution development of the upper capital structure theory, the interaction relationship of capital structure theory, recessive financial capital and "the capital structure puzzle" can be concluded: 1) all the capital structure theory before MM theory has insignificant guiding significance in financial value decision practice, which has become the natural theoretical soil for breeding "the capital structure puzzle"; 2) the proposal of the MM theory manages to solve "the capital structure puzzle", and it is the first in the history to solve "the capital structure puzzle". But the MM capital structure irrelevance theory could not take on the heavy historic responsibility with a reason that of the irrelevant logical consequence of enterprise value and capital structure in theory; 3) although the extrinsic research paradigm of capital structure theory has put forward the basic idea for solving "the capital structure puzzle" in static tradeoff based on the neoclassical economics research framework, but the uncertainties caused by the measurement method of value creation and recessive financial capital, such as financial distress cost or financial distress cost keep the "the capital structure puzzle" still a puzzle; 4) intrinsic research paradigm of capital structure theory based on the research framework of neoinstitutional economics has provided information transfer for solving "the capital structure puzzle", but the financial value decision of recessive financial capital such as agency cost under the condition of information asymmetry looks so feeble; 5) extrinsic and intrinsic research paradigm of capital structure theory based on the research framework of game economics manages to integrate the advantages of extrinsic research paradigm and intrinsic research paradigm to further dialyze and solve "the capital structure puzzle", but the era of knowledge economy has contributed great new factor capital for enterprise value creation, such as relationship capital, customer capital and brand capital. The diversity and controversy of the metric form of the value creation of recessive financial capital determines the present dilemma for "the capital structure puzzle".

The relationship of capital structure theory, recessive financial capital and "the capital structure puzzle" mentioned above can be described by Fig.1. 


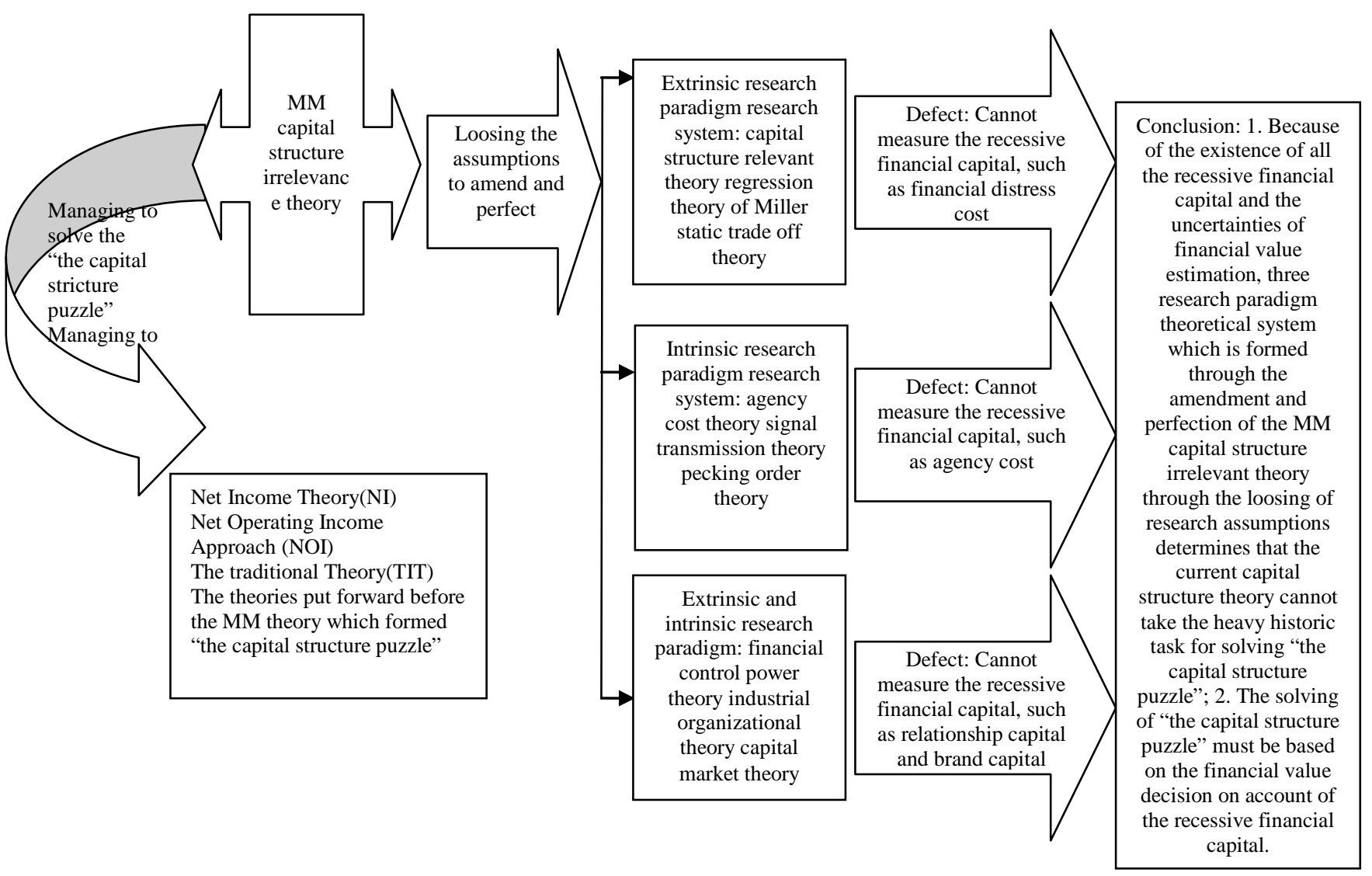

Fig. 1. The relationship of capital structure theory, recessive financial capital and "the capital structure puzzle"

According to the above analysis, to solve "the capital structure puzzle" must be based on the financial value decision on account of the recessive financial capital.

\section{CONCLUSION}

1. The existence of "the capital structure puzzle" is the product of "capital structure theory system jungle" formed in the research of capital structure in a multi-angle point view. It is also the direct result of the financial value contribution degree of recessive financial capital, such as relational capital, customer capital and reputation capital which are hard to measure in capital structure value decision practice.

2. The difference of financial value creation mechanism of recessive financial capital, such as relational capital, customer capital and reputation capital, the diversity of financial value estimation technique and the flexibility of financial value management method have influenced the conceptual framework and the theoretical support innovativeness of recessive financial capital. In the meanwhile, it has brought more challenges and uncertainties for the capital structure value decision practice. Those challenges and uncertainties have led to the existence of "the capital structure puzzle" in the capital structure value decision practice.
3. The objective existence of "the capital structure puzzle" directly drives the theoretical value of the research of recessive financial capital. Conversely, the research of recessive financial capital has provided a new analysis perspective for solving "the capital structure puzzle”.

\section{REFERENCES}

[1] Stewart C. Myers. The Capital Structure Puzzle [J].the journal of finance, 1984 (6): 575.(In Chinese)

[2] Harris, M.\&Raviv, A. Capital Structure and the Informational Role of Debt [J]. Journal of Finance, 1990 (45): 321-349. (In Chinese)

[3] Liu Wei, Li Guiping. The Application of Foreign Capital Structure Theory in Corporate Financial Decisions-The Survey Research Review of Foreign Capital Structure Theory [J]. Public Finance Research, 2012 (11): 61-65. (In Chinese)

[4] Luo Yunxuan, Wang Yonghai. The Reflection on the Serviceability of Western Capital Structure Theory in Our Country- Institutional Adaptation and Market Game Perspective [J]. Journal of Financial Research, 2007 (11): 67-82

[5] Tang Guozheng, Liu Li. Corporate Capital Structural TheoryRetrospect and Prospect [J]. Management World, 2006 (5): 158. 